\title{
Assessing Thinking Strategy of Numeracy Primary School Pupils
}

\author{
Nor'ain Mohd Tajudin \\ Sultan Idris Education \\ University, \\ Perak, Malaysia
}

\author{
Siti Rahaimah Ali \\ Institute of Teacher \\ Education Kota Bharu, \\ Kelantan, Malaysia
}

\author{
Noraini Idris \\ Sultan Idris \\ Education University, \\ Perak, Malaysia
}

\begin{abstract}
This study discusses the understanding level of numeracy based on the Model of Understanding Numeracy Level. Four stages in the model are de-coding, meaning-making, applications and analysis. The study employed a qualitative descriptive research. A total sample of 200 Primary Four, Year 5 pupils (9-10-year-old) from 20 Malaysian primary schools at the District of Kota Bharu, Kelantan was randomly selected for this study. The numeracy levels were identified by mathematics teachers' classroom observation assessment and researchers' observation through clinical interview. The findings showed that majority of the pupils (70 pupils) were at the application level identified by mathematics teachers' classroom observation assessment. However, majority of the pupils were at de-coding ( 70 pupils) and analysis (65 pupils) levels identified by researchers' observation through clinical interview conducted after the numeracy module was introduced to the pupils. Some excellence pupils were able to achieve the level of application and analysis. The findings also revealed that more pupils can reach the analysis level for Addition topic as compared to Division, Multiplication and Subtraction topics. This study contributes to the knowledge development and practice of teaching and learning, namely in numeracy understanding. The numeracy understanding model can elicit ideas to solve the real-life problems hence pupils will be confident and creative in solving mathematical problems.
\end{abstract}

\section{Keywords}

Model of Understanding Numeracy Level, de-coding, meaning-making, application, analysis, Year Four primary school pupils, mathematics teaching and learning.

\section{INTRODUCTION}

Everyone needs to be numerate to maximise their life chances and to make a positive contribution to society. Poor numeracy affects individuals' ability to succeed in the workplace and acts as a brake on the country's economic growth. Improving the national skills quota (from basic skills, including numeracy and literacy, to higher skills, such as engineering) is fundamental to increasing productivity and therefore economic growth. Numeracy is not limited to the ability to use numbers, to add, subtract, multiply and divide. Numeracy encompasses the ability to use mathematical understanding and skills to solve problems and meet the demands of day-today living in complex social settings. To have this ability, pupils need to be able to think and communicate quantitatively, to make sense of data, to have a spatial awareness, to understand patterns and sequences, and to recognise situations where mathematical reasoning can be applied to solve problems.

The Malaysian Government has identified basic literacy and numeracy skills as part of the key initiatives to improve student outcomes in Malaysia [1]. The introduction of the Literacy and Numeracy Screening (LINUS), a remedial programme in 2010 was motivated by two key findings. Firstly, the Ministry of Education found there were gaps in Malaysian students' literacy and numeracy skills. In 2008, about $13 \%$ of total Primary 1 population of that year failed to meet the targeted literacy (Bahasa Malaysia) skills. In the same year, an estimated 24\% in Primary four also fell short of the targeted numeracy skills. Secondly, research showed that failure to meet basic literacy and numeracy skills early in life meant students struggled to catch up with lessons. In 2008, about 32,000 students dropped out of school at various stages. With almost $100 \%$ passing rate of Primary Three students on the year 2013, the Government is convinced that LINUS is working. The LINUS 2.0, which is the English equivalvent, has been rolled out in all primary schools in early 2013.

In 2013, the Primary Three pupils were in Year Four, however, they was no assessment to determine pupils' understanding of numeracy continuously. This was due to lack of instruments or tools to assess student's understanding of numeracy. Understanding of numeracy in the early stages of learning will help students to understand the next lessons. Thus, the Model of Understanding Numeracy Level for Year Four Primary School Pupils in this study provides an instrument to identify pupils' numeracy level as well as numeracy ideas on topics in mathematics where pupils are given some complex tasks and activities involving de-coding, meaning-making, application and analyzing stages. Through these stages pupils will be more critical and creative in solving mathematical problems as well as inculcating pupils' higher-order thinking skills in learning mathematics.

\section{LITERATURE REVIEW}

Numeracy understanding framework model consists of four levels, namely the interpretation of the code (de-coding), the acquisition of knowledge (meaning-making), application, and analysation [2]. Understanding and numeracy teaching and learning is complex process ([3], [4]).

This model emphasizes the pupils' understanding of numeracy according to four levels mentioned as well as an opportunity for students to understand the concept of numeracy and the context before understanding further complex thinking. Secondly, it provides opportunities to explore with others such as in pairs, groups or the whole class discussion where different views can be gathered. Thirdly, it 
provides opportunities for student in creating new knowledge mainly to explain the results or decisions that they have made to peers and teacher. Thus, the numeracy understanding model can elicit ideas and associate relations between each other to solve the given problem [5].

Numeracy model can also be used as a checklist for both teachers and students to see levels of numeracy understanding, exploring thinking procesesses, and analysing questions. Numeracy model eases the students to express their everyday thought and adapt them to everyday life [6]. This model is easy to use as each stage or level had specific characteristics. The teacher as well as his/her students can think of various strategies used at the specified levels. At the beginning of the initial application using his model, it may take quite a long time to be adapted in the learning, but this finally will be a habit as teacher and students will be familiar with this stages. In addition, they can also use this numeracy model in other subjects.

In mathematical problem solving, students often had difficulties in identifying the initial step and always trying hard to determine the further steps in solving the problems [7]. This numeracy model involves different ways to solve problems There is not just one way to get the correct answer. There are four steps to be followed and this could facilitate the students in solving problems. Framework of this model is also consistent with the constructivist learning approach in learning, where new knowledge is related to what they already know, hence building their own understanding and creating new meaning. This approach can help students to recognize the characteristics of numeracy in everyday situations [8]. Based on the numeracy framework model, students can also develop their understanding of numeracy in the environment. This will help students to develop their intelligence so they can make better decisions in social, environmental, and everyday life. The model itself can act as an alternative transformation teaching tool for teachers to help them to use various innovative and creative teaching method.

The model framework of numeracy understanding level can trigger numeracy ideas deeply on topics in mathematics. Pupils will be given some examples of questions to be familiarise with and help students with the interpretation of the code (de-coding) and the acquisition of knowledge (meaning-making), then to the next stage of the application,and analysing [2]. By using this model, it can also help students creatively use their acquired knowledge to solve questions.

\section{CONCEPTUAL FRAMEWORK}

As mentioned above, there are four levels in the model. The following are description of each level.

\subsection{Stage 1: De-coding}

At this stage, the interpretation of the code used to ensure pupils express mathematical terminology used. For example, students should be able to state the basis for calculation of addition, subtraction, multiplication and divisions as well as the pupils are able to express terminology in respect of number, measurement, fractions, geometric shapes and so on. At this stage, students can list the words, ideas, language, and mathematical information and concepts adopted in the form of a map. At this stage, students learn vocabulary and numeracy for all the information, such as the geometry of the pupils can recognize the shape shown, draw a shape and reproduce the shape of the object to collect all the information, mathematical terms and categorize the mathematical key concepts [9].

After identifying the mathematical concept at this stage, students can identify the entity diagram to see the whole object but do not know the features. For example, the concept of geometry is observed as a whole entity and is not made up of components or attributes. Geometric shapes known by its shape overall, a physical diagram rather than components or properties that form. Students will contribute ideas through this process in a variety of views about numeracy. This can be done individually or involves a class of pupils. Teachers must ensure students are willing to give ideas to many so that they can obtain new ideas from students. This will encourage the students to recall what they have learned in order to generate new ideas to solve a problem of numeracy. After that, the students are asked to express their own opinion of what was given during the session to contribute their ideas. This will create ideas that are relevant in the eyes of the student based on their understanding.

At this level, students are able to identify mathematical concepts such as the number, basic calculation, measurement, shapes, space, and statistics. At this stage, students should be able to state the processes and procedures in mathematics. For example, students can express what operations involved to resolve any questions. At this stage, students can write initial thoughts about the process and procedures of the questions. For example, the addition of fractions and other mathematical operations. At this stage, pupils' understanding of the questions and the procedure will be able to produce new ideas with respect to numeracy. This will provide continuity to the existing knowledge after the students have gone through this stage. This process helps students in developing confidence to the students to solve the questions. It also encourages them to recall what they have learned in order to generate new ideas and explains how to get a basic fact before solving problems.

At this stage, students can illustrate and describe the main ideas of mathematics. Students at this level can reflect a key mathematical ideas, this is because the image is pure knowledge for someone who broke out a result of past experience of viable knowledge which came on spot [10].. This situation reflects the numeracy understanding concept of pupils as a result of what they have learned and what they display. Students at this level can also delegate their understanding of numeracy concepts in the form of a diagram. This representation is done repeatedly on the experience they have. For example, the students represent the knowledge of fractions, measurements and others using drawings, concrete materials and so on.

\subsection{Stage 2: Meaning-Making}

Students at this level are able to explain how to get the basic facts of mathematics, for example students can explain basic questions involving calculations to explain the operation and know what operation to use. In addition students can explain the process and procedures used to solve a question and the students to match the mathematical concepts after reading the questions. Students will also be able to give their own meaning to contribute ideas during the session and this will create ideas that are relevant based on their understanding. Students also learn how to get the basic facts of math and how math concepts can be understood based on the content of the questions. At this stage, students can explain the initial 
thoughts, ideas and questions to have a better understanding of a topic. Therefore, they will be able to create new ideas and continuation of the previous thinking on a topic after they have been through the process. At this stage, students were exposed on how to get different data and formulate them clearly or more meaningful to be described accurately and regularly. In other words, students can formulate the operations that will be used to get the answer [9].

At this stage, it encourages students to think about something such as a problem, question or topic, and then express their opinion. This will encourage the continuation of conceptual understanding through active reasoning and explanation for students to hear and share ideas, and encourage students to understand the various perspectives. Acquisition of knowledge is used when students solve problems numeracy, teachers can ask students to take time to think about a question or issue and share their views with their classmates. Knowledge acquisition can also be done in small groups, and then formulate their ideas to the whole class.

As a result of the acquisition of this knowledge, the students took turns presenting their views, listen carefully and ask questions to each other. One way to ensure a student listening to each other is to let they explain what they have found out and never tell what their own thoughts are running. Students will be able to anticipate on how to obtain different data can be formulated more clearly and regularly. In other words, students can formulate the operations used to get an answer. This stage also let students to be able matching students' thinking about problems in question or topic and later they can express their own views. This will promote their understanding through reasoning, sharing ideas and encourage students to understand various perspectives to solve problems in numeracy. Pupils will be able to match the mathematical concept of the acquisition of the knowledge gained.

At this stage, students can anticipate how to get different data. When a question is given, a student can expect to such data obtained from the questions. Then, students will match their thinking about the questions raised by the topics they learned. Here they will voice out their opinions and give ideas through a variety of perspectives both in numbers, calculating, measurement, shape, space, and statistics. Students will expect operations to be used for questions solving.

\subsection{Level 3: Application}

At this stage, students can complete the data obtained by making predictions, develop models and create concept maps to solve the questions and consider information or data to be applied to the solution [4].. Pupils also are able to associate the concept of numeracy in everyday life. For example the exchange concept can be applied in everyday life of pupils. Students at this level can select and use appropriate procedures to correct in the resolution of a question. The ability of students to solve related questions indicates whether students have mastered a concept or procedure in numeracy. In this application, the students can do problem solving of a question when they really understand the concept or procedure in numeracy. Pupils will be able to associate the concept of numeracy in their daily life so they can select appropriate procedures in probing questions [11].The ability of students to solve questions describes whether they can master a concept or understanding of numeracy. Students will also be able to determine the suitability of the principles to use in solving new problems by providing a logical reason about the decisions taken.

At this stage the students are smart to determine appropriate procedures in the solution of comprehension and numeracy skills and students also can acquire important and useful facts or numeracy concepts for questions solving. Students can view understanding and application of numeracy concepts based on questions or texts to different questions given. As a result the students will apply the data in a way to make predictions, model development, and research, imagine the scenario, or make concept maps to solve the questions and consider information or data to be applied to the solution of the given problem.

Pupils at this stage may be able to give any reason or justify their decision taken to solve new problems using the principles learned. Pupils will be able to determine the suitability of concepts and principles to use in solving new problems by giving reasonable grounds and in accordance with the facts of a concept of numeracy. Pupils can also recount an old problem to determine the principles that can be used to solve new problems and be able to apply mathematical concepts to solve a different problem. Here the students are already wise to consider information or data to be applied to any solution to the problem posed [2].

A study found students could not apply some problems earlier if a problem is not having a code interpretation process and acquisition of knowledge [12]. For example, students cannot solve a problem spontaneously if they do not learn basic operations. This is because they often expect a new or different problem caused by changes made in the basis of its calculation [13]. The findings of this research indicate that students cannot translate numeracy completely. Therefore, students need to be trained to form a representation prior to the application level.

\subsection{Stage 4: Analysing}

At this stage, students can prove mathematical concepts, procedures used, and mathematical facts to support response. Pupils will be able to determine the relationship between the evidence of the answers given where student is able to prove that each answer given using the appropriate mathematical concepts. This includes the making reasonable assumptions and gets a different view of the various mathematical concepts.

The purpose of the doing analysis is to see the thinking among students, where they have the opportunity to develop a good question that can provoke thought and investigate the topic. They can also describe the procedures used are based on facts and evidence provided. This will help students to 'brainstorm' in various types of questions on the topic of study and understand why they give such answers. The purpose of asking deep questions and interesting is to get at least the complexity and depth of the topic as well as to provide concrete arguments. Then, through a variety of ideas and arguments about the given topic or question will get a variety of information about topics studied and the answers given. This will produce students who can argue about mathematical concepts used.

Students can distinguish some reasonable assumptions and encourage them to be responsible for whatever evidence or argument specified at this level. This will increase their motivation to do the survey when answering a given question. 
Here, students can learn a new concept or topic; this will help the students to get the latest information about topics studied. The analysis can also be used when you are learning sessions and it is as a way to revive the curiosity of students. Analysis can also be used when you are near the end of the study in a topic, as a way to show students how the knowledge they have acquired about the topic helps them to ask questions and to argue in a more interesting process.

At this stage, students must dare to make a decision on a question or topic without fears. They must believe and confident with their answers when probing questions, this is because they need to ensure that all facts and concepts used in the analysis of a question is correct and timely. They are also able to demonstrate the concepts or facts used in the solution to support the answers given. Here too, students can determine the relationship between the evidence logically, be able to describe and argue about a fact or concept used to coincide with the answers given. Students at this level have to make decisions based on convincing evidence against a decision made. Pupils are confident with math concepts or terminology used and to ensure that all facts and concepts used for the analysis (William, 2000).

\section{OBJECTIVES OF THE STUDY}

A discussion of numeracy in the primary school should be considered in the context of the mathematics curriculum for the primary school. The desire to have a numerate or mathematically literate population is met by sowing the foundations of mathematics and numeracy in the early years and through primary education. Mathematics is part of everyday life. Being numerate is about being competent in dealing with mathematically related aspects of life such as shopping, following directions, reading timetables and solving problems.

The purpose of the study was to identify the level of numeracy level attain by a cohort of Malaysian primary school pupils (Primary Four pupils, 9-10-year-old). In addition, we were interested to examine the pupils' level of numeracy according to the mathematical topics and the impact towards mathematics achievement. We sought data relevant to the following three research questions:

1. What are the levels of numeracy among Primary Four pupils?

2. What are the levels of numeracy according to mathematical topics among Primary Four pupils?

\section{METHODOLOGY}

\subsection{Design}

This study employed a qualitative descriptive research design as our interest to generate information about the current status of the numeracy level of Primary Four pupils.

\subsection{Participants}

A total of 200 pupils from 20 Malaysian primary schools at the District of Kota Bharu Kelantan participated in the present study. Participants in this study were Primary Four, Year 5 pupils (9-10-year-old). A random sampling technique was chosen from each school as the population in this study was heterogeneous. The technique is appropriate in order to obtain selection representative sample [14]. All primary pupils in Malaysia were required to complete a common mathematics curriculum in the first three years of primary school. Table 1 presents the distribution of participants based on Gender.
Table 1: Distribution of participants based on Gender

\begin{tabular}{|c|c|c|}
\hline Gender & $\begin{array}{c}\text { Number of } \\
\text { student }\end{array}$ & Percentage (\%) \\
\hline Male & 42 & 12 \\
\hline Female & 56 & 16 \\
\hline & 200 & 100 \\
\hline
\end{tabular}

\subsection{Numeracy Model Tasks Module}

The Numeracy Model Task Module (NMTM) provide numeracy ideas on topics in mathematics where pupils are given some complex tasks and activities involving de-coding, meaning-making, application and analyzing stages. The module consisted of 17 topics according to Year Four Primary School Curriculum Standard. A series of lectures and workshops were conducted to transfer knowledge related to the NMTM to 20 Year-Four mathematics teachers in the District of Kota Bharu, Kelantan. These activities were done to explain about the numeracy model, the module, and how to identify pupils' level of numeracy understanding. Levels of numeracy understanding were assessed in two ways: (i) classroom observation assessment by mathematics teachers, and (ii) researchers' observation through clinical interview. Pupils' level of numeracy understanding can be identified using the same method as explained above in assessing mathematics achievement test.

\subsection{Procedures}

There were three phases in the study. The first phase was concerned with the development and fine-tuning of NMTM. During the second phase, we pilot tested the task module to allow for familiarization process of the data collection processes. The third phase involved the implementation of the NMTM. During the implementation of the NTM, the teachers collected data on the level of numeracy understanding for 10 selected students in his/her class. The researchers also conducted clinical interviews with the same 10 pupils at the end of the study to identify their level of numeracy understanding.

Prior to phases two and three, permissions were obtained from the Educational Planning and Research Department (EPRD) of the Ministry of Education, Malaysia and the Kelantan State Education Department to carry out the research. In addition, school administrations and parents were informed about the study and ethical clearances were obtained from parents, participating pupils and school principals.

\subsection{Data Analysis}

Descriptive statistics such as frequencies and percentages were used to describe the background information about the respondents who participated in this study as well as the level of numeracy understanding.

\section{RESULTS AND DISCUSSION}

Two research questions were of interest to the present study. Data relevant to these research questions are presented below.

Research Question 1: What are the levels of numeracy among Primary Four pupils? 


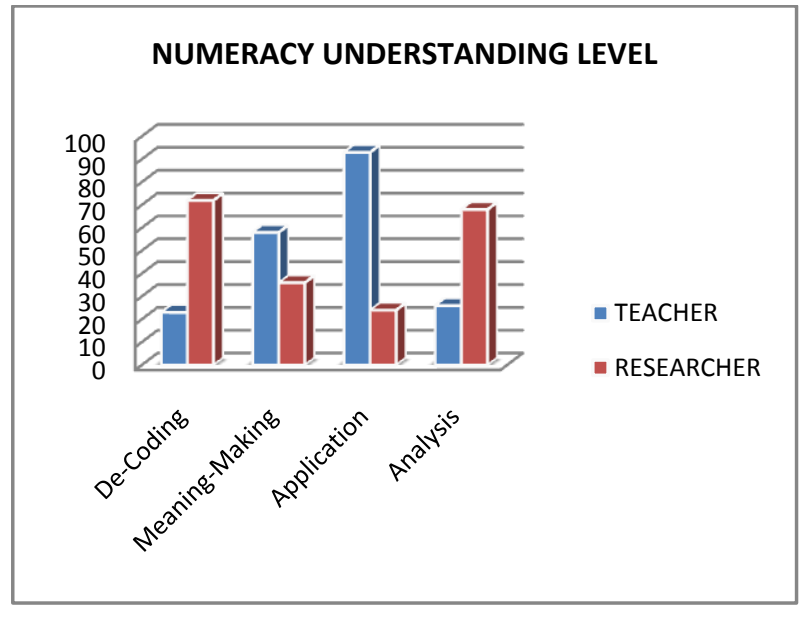

Figure 2: Numeracy Understanding Level

Figure 2 illustrates the level of numeracy understanding for 200 Primary Four pupils from 20 primary schools at the District of Kota Bharu Kelantan. As mentioned above, the numeracy levels were identified based on mathematics teachers' classroom observation assessment and researchers' observation through clinical interview. From Figure 1, majority of the pupils (70 pupils) were at the application level based on mathematics teachers' classroom observation assessment. However, majority of the pupils were at $d e$ coding (70 pupils) and analysis (65 pupils) levels based on researchers' observation through clinical interview conducted after the numeracy module was introduced to the pupils. Some excellence pupils were able to achieve the level of application and analysis even though the answers were incorrect.

\section{Research Question 2: What are the levels of numeracy according to mathematical topics among Primary Four pupils?}

Table 3 showed the frequencies and percentages of numeracy understanding level according to the chapters taken from Primary Four Mathematics Syllabus. In this study, there were four chapters that had been assessed through researchers' observation through clinical interview.

The chapters were Addition (Chapter 2), Subtraction (Chapter 3), Multiplication (Chapter 4) and Division (Chapter 5). From Table 3, the findings showed that for Addition topic, about one third of pupils can reached analysis level, and about one third of them only reached the level of de-coding. For Subtraction topic, it was found that about one third of pupils can reached analysis level, and about one quarter of them only reached the level of de-coding. Only 8\% (16) of the pupils reached the application level. For Multiplication topic, it was found that about 1/4 of pupils reached analysis level, and about $2 / 5$ of them only reached the level of de-coding. For the Division topic, only $1 / 4$ of the pupils reached the analysis level. About $2 / 5$ of pupils reached the de-coding level. The analyses indicated that more pupils can reach the analysis level for Addition topic as compared to Division, Multiplication and Subtraction topics. This is not surprising since majority of the pupils had mastered the Addition concepts. In addition, from the clinical interview, the researchers found that the level of numeracy understanding also was affected by pupils' mathematical conceptual knowledge.
Table 3: Frequencies and Percentages of Numeracy Understanding Level according to Chapters

\begin{tabular}{|c|c|c|c|c|c|c|c|c|}
\hline \multirow{3}{*}{$\begin{array}{l}\text { CHAPTER } \\
\text { QUESTION }\end{array}$} & \multicolumn{8}{|c|}{ LEVEL } \\
\hline & \multicolumn{2}{|c|}{$\begin{array}{c}1 \\
\text { DE CODING }\end{array}$} & \multicolumn{2}{|c|}{$\begin{array}{c}2 \\
\text { MEANING } \\
\text { MAKING }\end{array}$} & \multicolumn{2}{|c|}{$\begin{array}{c}3 \\
\text { APPLICATION }\end{array}$} & \multicolumn{2}{|c|}{$\begin{array}{c}4 \\
\text { ANALYSIS }\end{array}$} \\
\hline & $\mathrm{f}$ & $\%$ & $\mathrm{f}$ & $\%$ & $\mathrm{f}$ & $\%$ & $\mathrm{f}$ & $\%$ \\
\hline $\begin{array}{c}\text { CHAPTER 2 } \\
\text { Question 2 }\end{array}$ & 78 & 39.0 & 34 & 17.0 & 13 & 6.5 & 75 & 37.5 \\
\hline $\begin{array}{l}\text { CHAPTER } 3 \\
\text { Question } 3\end{array}$ & 79 & 39.5 & 60 & 30.0 & 16 & 8.0 & 45 & 22.5 \\
\hline $\begin{array}{l}\text { CHAPTER } 4 \\
\text { Question } 5\end{array}$ & 84 & 42.0 & 33 & 16.5 & 27 & 13.5 & 56 & 28.0 \\
\hline $\begin{array}{l}\text { CHAPTER 5 } \\
\text { Question } 6\end{array}$ & 76 & 38.0 & 27 & 13.5 & 47 & 23.5 & 50 & 25.0 \\
\hline
\end{tabular}

\section{CONCLUSION}

Numeracy understanding level model is an innovation designed to suit the curriculum in Malaysia. This model is one of the "Thinking Strategies" and parallel with the implementation of School Based Assessment, which now is carried out in all schools levels in Malaysia. The framework of this model provides numeracy ideas on topics in mathematics where pupils are given some complex tasks and activities involving de-coding, meaning-making, application and analyzing stages. This study provides evidence that through the implementation of the model, some pupils were able to achieve the level of application and analysis. This study contributes to the knowledge development and practice of teaching learning, namely in numeracy understanding. The numeracy understanding model can elicit ideas to solve the real-life problems hence pupils will be more critical and creative in solving mathematical problems.

\section{ACKNOWLEDGMENT}

The authors would like to express their appreciation to the Ministry of Higher Education Malaysia and EPU through the Knowledge Transfer Program Grant (Reference Code Number 057007-2014-003-01) for the financial support in this project.

\section{REFERENCES}

[1] Ministry of Education (2010). Rancangan Malaysia Kesepuluh:Bab 5, Membangun dan Mengekalkan Model Insan Bertaraf Dunia. Kuala Lumpur: Kementerian Pelajaran Malaysia.

[2] Luke, A., \& Freebody, P. (2009). Critical numeracy, Numeracy in the news, Australia; Faculty of Education, University of Tasmania.

[3] Ball, D. L. (2002). Mathematical proficiency for all students: Toward a strategic research and development program in mathematics education. USA: RAND Education/Science and Teknology Policy Institute.

[4] Kilpatrick, J., Swafforce \& Findell, B. (2001). All adding it up: Helping children learn mathematics. Washingston DC: National Academic Press.

[5] Ludlow, A. S. (2004). Metaphor and numerical diagrams in the arithmetical activity of a fourth grade class. Journal Research Mathematics Education, 35, 34.

[6] Munn, P. (2005). Young children's rights to numeracy. International Journal of Early Childhood, 37( 3), 61-77. 
[7] Watson, J. M., Callingham, R., \& Donne, J. (2008). Establishing pedogogical content knowledge for teaching statistic, In C. Batanero, G. Burrill, C. Reading \& A. Rossman (2008), Joint ICMI/IASE Study: Teaching Statictics in School Mathematics. Proceedings of the ICMI Study 18 and 2008 IASE Round Table Conference. Monterrey: ICMI and IASE and JASE. Available from www.stat.auckland.ac.nzl-iase/publications.

[8] Gal, I. (2002). Adult numeracy development:theory, research, practice. Cresskill,NJ: Hampton Press.

[9] Anghileri, J. (2000). Teaching number sense. New York: Continum International Publication Group

[10] Steffe, L. P. (2009). Teaching experiment methodology: Underlying principles and essencial element In R.Lesh \& A.E. Kelly. Hillsdale NJ: Erlbaum.
[11] Siti Rahaimah Ali \& Noraini Idris. (2013) A model to identify the level of numeracy understanding of primary school pupils: a case study. Jurnal Pendidikan Sains \& Matematik Malaysia,3(2), 24-42.

[12] Carpenter, T. P., Moser, J.M., \& Bebout, H.C. (1988). Representation of addition and subtraction word problems. Journal for Research in Mathematics Education, 19(4), 345-357.

[13] White, A. L. (2010). Numeracy, literacy and newman's error analysis. Journal of Science and Mathematics Education in Shouheast Asia. 3(2), 129-148.

[14] Wiersma, W., \& Jurs, S. G. (2005). Research methods in education (8th ed.). Boston: Allyn \& Bacon. 